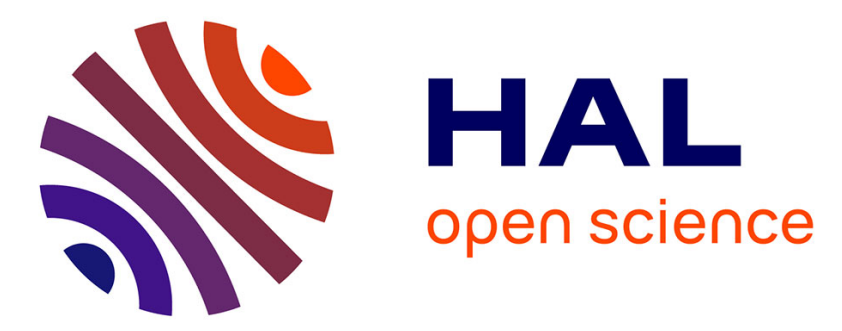

\title{
Inspection Interval Estimation: A Fuzzy Logic Based RBI Analysis Approach
}

R. Chandima Ratnayake

\section{To cite this version:}

R. Chandima Ratnayake. Inspection Interval Estimation: A Fuzzy Logic Based RBI Analysis Approach. IFIP International Conference on Advances in Production Management Systems (APMS), Sep 2014, Ajaccio, France. pp.334-341, 10.1007/978-3-662-44739-0_41 . hal-01388509

\section{HAL Id: hal-01388509 \\ https://hal.inria.fr/hal-01388509}

Submitted on 27 Oct 2016

HAL is a multi-disciplinary open access archive for the deposit and dissemination of scientific research documents, whether they are published or not. The documents may come from teaching and research institutions in France or abroad, or from public or private research centers.
L'archive ouverte pluridisciplinaire HAL, est destinée au dépôt et à la diffusion de documents scientifiques de niveau recherche, publiés ou non, émanant des établissements d'enseignement et de recherche français ou étrangers, des laboratoires publics ou privés.

\section{(c)(1)}

Distributed under a Creative Commons Attribution| 4.0 International License 


\title{
Inspection Interval Estimation: A Fuzzy Logic Based RBI Analysis Approach
}

\author{
R.M. Chandima Ratnayake \\ Department of Mechanical and Structural Engineering and Materials Science, \\ University of Stavanger, Stavanger, Norway \\ (chandima.ratnayake@,uis.no)
}

\begin{abstract}
Risk based inspection analysis (RBIA) on offshore oil and gas $(\mathrm{O} \& \mathrm{G})$ production systems optimize level of in-service inspection. The potential failure risk of a system, a sub-system or a thickness measurement location (TML) of O\&G production systems comprise the consequence of failure $(\mathrm{CoF})$ and probability of failure $(\mathrm{PoF})$. A tailor-made risk matrix supports the estimation of maximum inspection intervals. When the inspection intervals are calculated using a risk matrix, suboptimal classification tends to occur as there are no means to incorporate actual circumstances at the boundary of the input ranges or at the levels of linguistic data and risk categories. This manuscript suggests a fuzzy inference system (FIS) to overcome the aforementioned. Membership functions and the rule base development have been carried out in alignment with a tailor-made risk matrix which has been utilized by a production plant owner operator organization. A rule view and a calculation result have been demonstrated to illustrate the methodology.
\end{abstract}

Keywords: Risk based inspection analysis, production system, inspection interval, fuzzy inference system.

\section{Introduction}

The performance of production and/or process plants are sustained by appropriate inspection planning and scheduling $[1,2]$. However, in this context, it is vital to determine the optimal inspection intervals in terms of a criteria of interest $[3,2]$. Consequently, risk based inspection analysis (RBIA) has been accepted over the last few years as a method for prioritizing the in-service inspection of a plant as well as for estimating corresponding inspection intervals [4]. These methods have been developed nationally (e.g. American Petroleum Institute (API), a number of private organizations (particularly in the petrochemical industry), etc.) [5] and internationally (e.g. RIMAP - Risk based inspection and maintenance procedures for European industries) [6]. The importance of risk was recognized principally as an important measure in assuring system safety [7]. However, there is a fundamental challenge in the mathematical modeling of RBIA to perform optimum maintenance as a subject [8].

The mathematical modeling enables mitigating subjective judgments based on limited information and also, some of the inherent challenges present in the current RBIA $[8,9]$. Alternatively, it mitigates the significant variability and discrepancy present in the current inspection interval estimations. For instance, a report published on a case study evaluation of an onshore process plant revealed that "subjec- 
tive judgments based on limited information did lead to some significant differences in inspection periods" [5]. It also revealed that although "generally, the inspection periods reflected the assessed risk", "considerable scatter was apparent in the data and some participants exhibited greater conservatism in their assessments than others" [5]. The same report suggests that "software, expert systems and expert judgment all have merits, greater integration of these elements might be beneficial" [5]. Hence, it is vital to develop expert systems to support expert judgments and alternatively to develop sophisticated software to minimize the variability present in estimating inspection periods (i.e. inspection intervals).

This manuscript proposes a fuzzy logic based expert system for estimating inservice inspection intervals [10]. The estimation of in-service inspection intervals is based on PoF, CoF and currently established values of inspection intervals with respect to different risk levels.

\section{Industrial Challenge}

Currently, recommended practices, standards (e.g. DNV-RP-G101), operator company procedures, etc., provide decision matrices for estimating inspection intervals (i.e. time to inspect) [11]. However, when the classifications are carried out, there is no formal mechanism to incorporate data and information at the boundaries of the risk categories (i.e. alternatively at the boundaries of the ranges and levels of linguistic data). This is mainly due to the fact that there are no means to incorporate real data (qualitative or quantitative) in a consistent manner in estimating the maximum allowable time intervals. For instance, along a boundary, the spontaneous jumps of risk classification together with recommended inspection intervals (e.g. $\mathrm{VH}$ to $\mathrm{H}$ : the recommended inspection interval changes from 6 months to 48 months) hinder realistic values depending on the estimated PoF and CoF, leading to suboptimal inspection interval estimations (see Fig. 1). Fig.1 illustrates such a risk matrix along with relevant maximum inspection intervals that have been utilized for piping RBISIA (i.e. in an operator organization which owns a production and process plant).

Due to the lack of a consistent approach, the inspection interval recommendations made are mostly confined to the PoF intervals, CoF intervals, and corresponding inspection interval values in an ad hoc manner dependent on the person who is involved in the analysis. Hence, it is vital to have a consistent approach to incorporate $\mathrm{PoF}, \mathrm{CoF}$ and inspection intervals.

\section{$3 \quad$ Methodology}

In order to cater for rapid changes (in inspection interval) at the boundaries of each risk level (see Fig.1), fuzzy membership functions have been introduced for each PoF, CoF and inspection interval. The introduction of fuzzy membership functions enables the inspection interval estimation to be made more realistic. Furthermore, a fuzzy inference system (FIS) enables the mitigation of discrepancies that may occur during the risk assessment process as a result of simultaneous considera- 
tion of different $\mathrm{PoF}$ and $\mathrm{CoF}$ ranges of values for estimating maximum inspection intervals.

\subsection{Risk Matrix}

During the detailed risk analysis process, the static mechanical pressure systems are subject to an investigation of PoF and $\mathrm{CoF}$ according to the categorization presented in Fig.1. This is a $5 \times 5$ matrix, indicating levels of both PoF and CoF whilst providing five risk levels (i.e. VL, L, M, H and VH). These risk levels represent a combination of $\mathrm{PoF}$ and $\mathrm{CoF}$ based on the relevant numerical value ranges. The numerical value ranges for PoF and CoF have been retrieved from the documentation pertaining to the case study plant operator's organizations (see Fig. 1). In addition, the corresponding maximum inspection interval (in months) has been indicated within the parenthesis under each risk level.

\begin{tabular}{|c|c|c|c|c|c|c|c|c|c|c|c|c|}
\hline \multirow{6}{*}{ 눙 } & ذँ & PoF & 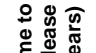 & \multicolumn{9}{|c|}{ Risk level [maximum inspection interval (MII) in months] } \\
\hline & VH & $>1 \mathrm{E}-2$ & $<3$ & $\begin{array}{c}\mathrm{VL} \\
(144)\end{array}$ & $\begin{array}{c}\mathrm{L} \\
(120)\end{array}$ & $\begin{array}{c}M \\
(72)\end{array}$ & $\begin{array}{l}\mathrm{VH} \\
(6)\end{array}$ & $\begin{array}{l}\text { VH } \\
(6)\end{array}$ & $\begin{array}{l}\text { VH } \\
(6)\end{array}$ & $\begin{array}{l}\mathrm{VH} \\
(6)\end{array}$ & $\begin{array}{l}\mathrm{VH} \\
(6)\end{array}$ & $\begin{array}{l}\text { VH } \\
(6)\end{array}$ \\
\hline & H & $(1 \mathrm{E}-2-1 \mathrm{E}-3)$ & $(3-7)$ & $\begin{array}{c}\mathrm{VL} \\
(144) \\
\end{array}$ & $\begin{array}{c}\mathrm{L} \\
(120)\end{array}$ & $\begin{array}{c}M \\
(72)\end{array}$ & $\begin{array}{c}\mathrm{H} \\
(48)\end{array}$ & $\begin{array}{c}H \\
(48)\end{array}$ & $\begin{array}{c}\mathrm{H} \\
(48) \\
\end{array}$ & $\begin{array}{l}\mathrm{V} \\
\mathrm{VH} \\
(6)\end{array}$ & $\begin{array}{l}\text { (v) } \\
\text { VH } \\
(6)\end{array}$ & $\begin{array}{l}\text { VH } \\
\text { (6) }\end{array}$ \\
\hline & M & $(1 \mathrm{E}-3-1 \mathrm{E}-4)$ & $(7-15)$ & $\begin{array}{l}\mathrm{VL} \\
(144)\end{array}$ & $\begin{array}{c}\mathrm{VL} \\
(144)\end{array}$ & $\begin{array}{c}\mathrm{L} \\
(120)\end{array}$ & $\begin{array}{c}M \\
(72)\end{array}$ & $\begin{array}{c}M \\
(72)\end{array}$ & $\begin{array}{c}\mathrm{H} \\
(48)\end{array}$ & $\begin{array}{c}\mathrm{H} \\
(48)\end{array}$ & $\begin{array}{c}\mathrm{H} \\
(48)\end{array}$ & $\begin{array}{c}\mathrm{H} \\
(48)\end{array}$ \\
\hline & L & $(1 \mathrm{E}-4-1 \mathrm{E}-5)$ & $(15-30)$ & $\begin{array}{c}\frac{1}{V L} \\
(144)\end{array}$ & $\begin{array}{c}\mathrm{VL} \\
(144)\end{array}$ & $\begin{array}{c}\frac{1}{L} \\
(120)\end{array}$ & $\begin{array}{c} \\
(120)\end{array}$ & $\begin{array}{c}M \\
(72)\end{array}$ & $\begin{array}{c}M \\
(72) \\
\end{array}$ & $\begin{array}{c}M \\
(72)\end{array}$ & $\begin{array}{c}\frac{M}{M} \\
(72)\end{array}$ & $\begin{array}{c}M \\
(72)\end{array}$ \\
\hline & VL & $<1 \mathrm{E}-5$ & $>30$ & $\begin{array}{l}\mathrm{VL} \\
(144)\end{array}$ & $\begin{array}{c}V L \\
(144)\end{array}$ & $\begin{array}{l}\mathrm{VL} \\
(144)\end{array}$ & $\begin{array}{c}\mathrm{L} \\
(120)\end{array}$ & $\begin{array}{c}\mathrm{L} \\
(120)\end{array}$ & $\begin{array}{c}\mathrm{L} \\
(120)\end{array}$ & $\begin{array}{l}M \\
(72)\end{array}$ & $\begin{array}{c}M \\
(72)\end{array}$ & $\begin{array}{l}M \\
(72)\end{array}$ \\
\hline \multirow{4}{*}{\multicolumn{2}{|c|}{$\begin{array}{l}\text { *Potential } \\
\text { loss of life } \\
\text { **000' } \\
\text { Norwegian } \\
\text { Krone }\end{array}$}} & \multicolumn{2}{|c|}{$\begin{array}{c}\text { Safety CoF (*PLL due } \\
\text { to a release) }\end{array}$} & $<1 \mathrm{E}-5$ & \multicolumn{2}{|c|}{$(1 E-4-1 E-5)$} & \multicolumn{3}{|c|}{$(1 E-3-1 E-4)$} & \multicolumn{2}{|c|}{$\begin{array}{c}(1 \mathrm{E}-2-1 \mathrm{E}- \\
3)\end{array}$} & $>1 \mathrm{E}-2$ \\
\hline & & \multicolumn{2}{|c|}{$\begin{array}{c}\text { Economical CoF } \\
\left({ }^{*} \mathrm{KNOK}\right)\end{array}$} & $<50$ & \multicolumn{2}{|c|}{$(50-500)$} & \multicolumn{3}{|c|}{$(500-5000)$} & \multicolumn{2}{|c|}{$(5000-50000)$} & $>50000$ \\
\hline & & Cof Cate & gory & $\mathrm{VL}$ & $\bar{L}$ & & & $M$ & & & & $\mathrm{VH}$ \\
\hline & & \\
\hline
\end{tabular}

Fig. 1. RBI matrix (maximum inspection interval in months).

\subsection{Probability of Failure Assessment}

In essence, the piping equipment is organized into corrosion groups which can contain several degradation mechanisms. Two models have mainly been used for evaluating the probability of failure $(\mathrm{PoF})$ of piping equipment due to degradation: I. a susceptibility model for stainless steels; and II. a rate model for carbon steels.

Susceptibility models are used when the PoF is related to operating conditions. In this context, for a given set of conditions that are constant over time, the PoF also remains constant over time. This indicates that it is not easy to monitor the development of damage mechanisms by using inspection. Hence, actions are related to the monitoring of key process parameters, which are used as a trigger for inspection. DNV-RP-G101, Appendix A [11] provides guidance about typical materials and environmental conditions where this model is expected to be applicable and suggest values for PoF for typical conditions. For the susceptibility models there are two governing conditions required for degradation: I. wet environment; and II. temperature. The results from the monitoring of these conditions are the most important in setting the probability. 
Rate models have increasing probability over the time, which makes it difficult to express as one probability value. Even though 'time to release' is itself not a probability expression, it explains the speed at which the probability increases, and therefore represents a useful profile of the probability. Hence, the development of degradation is measured by inspection. Then, the PoF is documented as an estimated 'time to release', based on the wall thickness and degradation rate on the area found to have the shortest time to release. In corrosion loops, both stagnant and varying flow conditions indicate very different estimated time to release (leak). Hence, the time to inspection is split among them in order to obtain the optimal time to inspection and this is reflected in the RBI analysis.

This manuscript provides a knowledge based engineering approach with the help of a fuzzy logic based inference system for estimating the inspection interval using a tailor-made risk matrix.

\subsection{Fuzzy Logic Based Inference System}

A 'pure fuzzy logic system' consists of a fuzzy rule base, which comprises a collection of fuzzy IF-THEN rules. These rules are utilized by the fuzzy inference engine to determine a mapping from fuzzy sets in the input universe of discourse $U$ $\subset R^{n}$ to fuzzy sets in the output universe of discourse $V \subset R$ based on fuzzy logic principles. The fuzzy IF-THEN rules follow the form below:

$$
\mathrm{R}^{(1)}: \text { IF } x_{1} \text { is } F_{1}^{1} \text { and } \ldots x_{n} \text { is } F_{n}^{1} \text { THEN y is } G^{1}
$$

where $F_{i}^{j}$ and $G^{j}$ are fuzzy sets, $x=\left(x_{1}, x_{2}, \ldots, x_{n}\right)^{T} \in U$ and $y \in V$ are input and output linguistic variables which belong to the input and output universes, respectively, and $j=1,2, \ldots, m$. Practical experience reveals that these fuzzy IF-THEN rules provide a convenient framework to incorporate human expert knowledge. In Eq. (1), each fuzzy IF-THEN rule defines fuzzy set $F_{1}^{j}, F_{2}^{j} \ldots F_{n}^{j} \Rightarrow G^{j}$ for $i=1$, $2, \ldots, n$, in the product space $U \times V$. Expert opinions and data/information retrieved from different sources are taken into the mathematical model using the aforementioned rules. The main focus is to enhance the discerning power in the risk analysis process, whilst minimizing the uncertainties that may occur in dealing with the linguistic variables of the risk levels (i.e. $\mathrm{H}, \mathrm{VH}, \mathrm{VL}$, etc.) at the boundaries of quantitative ranges. Essentially, membership functions (MFs) are developed with experienced personnel who are familiar with the risk analysis process [12]. Then, along with a rule base, MFs provide the possibility of recycling experts' knowledge in a consistent manner.

In 1975, Mamdani built one of the first fuzzy systems which used a set of fuzzy rules supplied by experienced human operators to control a steam engine and boiler combination [13]. To date, Mamdani's approach has been successfully applied to a variety of industrial processes and consumer products [14]. Fig. 2 illustrates the work process of the proposed fuzzy inference system. 


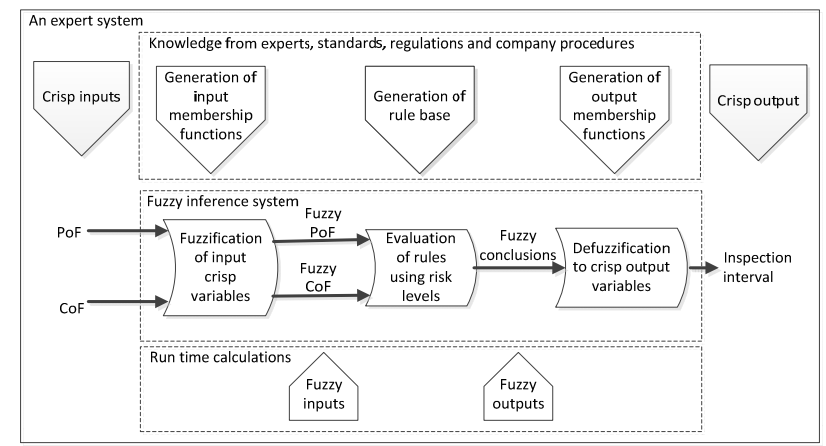

Fig. 2. An expert system for estimating maximum inspection intervals.

The PoF, time to release (TTR), safety consequence of failure, which is estimated by potential loss of life (PPL) (i.e. $\mathrm{CoF}_{\mathrm{PPL}}$ ) and economic consequence of failure (i.e. $\mathrm{CoF}_{\mathrm{Econ}}$ ) have been selected as the input variables. The inspection interval has been selected as the output. These variables consist of quantitative, qualitative and judgmental (i.e. linguistic) data. For each of the aforementioned variables, there is an associated membership function, which is established with the help of data, information and expert opinion [13]. The fuzzification process aids fuzzifiying the inputs by determining the value of the membership functions corresponding to the different inputs. Furthermore, instead of restricting the user to a single, crisp, input value, this process allows an interval of values to be given, with values near the center of the interval being assumed to be 'more certain' than those near the edges, and the width of the interval indicating the amount of uncertainty present in the different input variables. The aforementioned has been achieved by associating appropriate membership functions (MF) for the input variables. Using an appropriate MF, the user has 'more confidence' that the input parameter lies relatively closer to the center of the interval than at the edges. In this study the author has incorporated triangular membership functions [15].

The fuzzy inference system (FIS) parameters were selected as follows: 'And' method with 'minimum', 'Or' method with 'maximum', 'Implication' with 'minimum', 'Aggregation' with 'maximum' and 'Defuzzification' with 'centroid' algorithm. Fuzzy rule bases were developed using the table-look-up approach (see Fig. 1). The toolbox simulator of the MATLAB (R2011a) tool was utilized to implement a fuzzy criticality ranking system [16].

\section{$4 \quad$ Fuzzy Logic Based Modeling}

\subsection{Membership Functions for PoF}

In essence, the PoF per year has been related to degradation mechanisms in the susceptibility model. At the same time, the TTR has been utilized in the rate models to express the speed at which the probability increases (note: the probability related to rate models is a variable with time). The PoF is also subjected to an analysis for both external and internal failure mechanisms. The membership functions 
(MFs) for inputs PoF and TTR have been developed based on data, information and expert opinions (see Fig. 3 and Fig. 4).

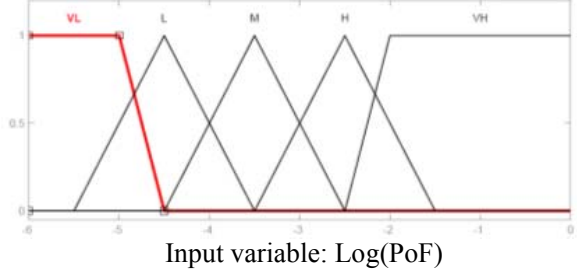

Fig. 3. MF for PoF.

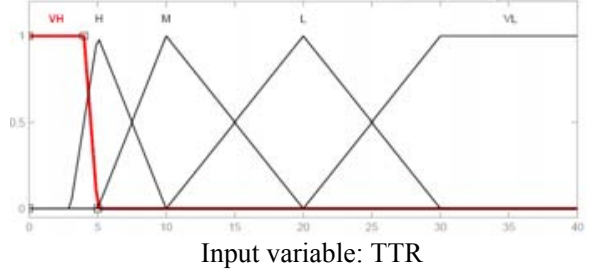

Fig. 4. MF for TTR.

\subsection{Membership Functions for CoF}

The $\mathrm{CoF}_{\mathrm{PPL}}$ values are estimated by quantitative risk analysis. The $\mathrm{COF}_{\mathrm{Econ}}$ values are determined based on the inputs from relevant operation and process personnel (production loss) and from piping/vessels discipline engineers (repair costs). Fundamentally, $\mathrm{COF}_{\mathrm{Econ}}$ covers costs related to loss of production and costs for repair in the case of a leak. Consequence of loss of functionality is also considered as an economic loss due to reduced or lost production and/or major repair cost, not necessarily given a leak or shutdown of equipment. For instance, typical loss of functionality is mostly related to failure of internals in vessels and coolers. However, in this manuscript the values of $\mathrm{CoF}_{\mathrm{PPL}}$ and $\mathrm{COF}_{\mathrm{Econ}}$ have been retrieved from the tailor-made company specific topside inspection manual of the case study operator company. The MFs for inputs $\mathrm{CoF}_{\mathrm{PPL}}$ and $\mathrm{COF}_{\mathrm{Econ}}$ have been developed based on data, information and experts' opinions (see Fig. 5 and Fig. 6).

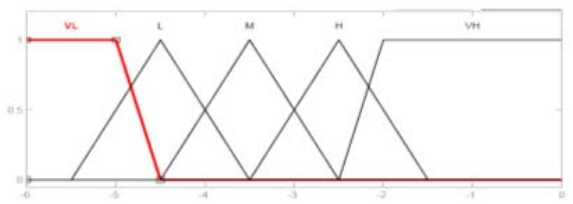

Input variable: $\log \left(\mathrm{CoF}_{\mathrm{PLL}}\right)$

Fig. 5. MF for $\mathrm{CoF}_{\mathrm{F}}$

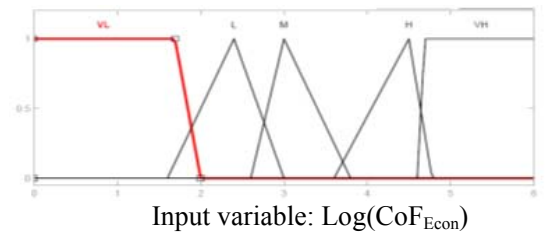

Fig. 6. $\mathrm{MF}$ for $\mathrm{COF}_{\mathrm{Econ}}$.

The membership function for maximum inspection interval (MII) is illustrated in Fig. 7.

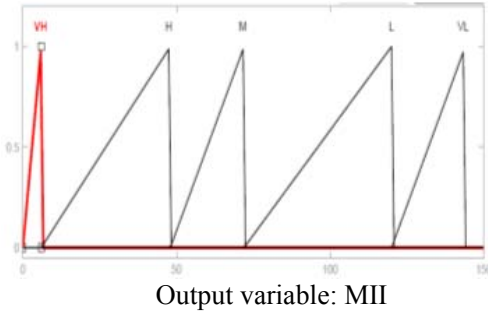

Fig.7. MF for MII.

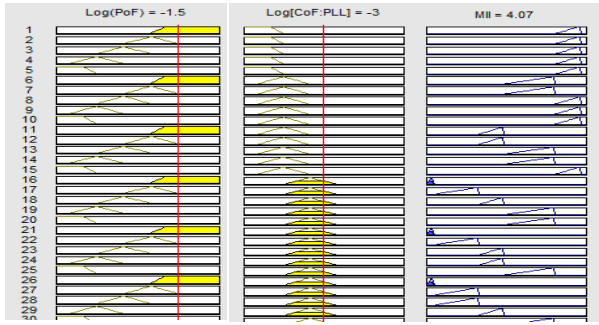

Fig.8. Calculation of MII when $\mathrm{PoF}=1 \mathrm{E}-1.5$ and $\mathrm{CoF}_{\mathrm{PLL}}=1 \mathrm{E}-3$ (i.e. $\mathrm{MII}=4.07$ ). 


\section{$5 \quad$ Analysis and Results}

PoF and $\mathrm{CoF}_{\mathrm{PLL}}$ have been utilized to illustrate the calculation of MII (see Fig. 8). Using the table look-up approach (see Fig.2) to estimate MII in relation to different PoF and $\mathrm{CoF}_{\mathrm{PLL}}$ levels, 45 rules have been generated. Fig. 8 illustrates approximately 29 rule views and the corresponding calculation of $\mathrm{MII}$ (i.e. $\mathrm{MII}=$ 4.07) for $\mathrm{PoF}=1 \mathrm{E}-1.5$ and $\mathrm{CoF}_{\mathrm{PLL}}=1 \mathrm{E}-3$.

It is possible to use a similar approach for PoF \& $\mathrm{CoF}_{\mathrm{Econ}}$ vs. MII; TTR \& $\mathrm{CoF}_{\mathrm{PLL}}$ vs. MII; and TRR \& $\mathrm{CoF}_{\text {Econ }}$ Vs. MII. All the combinations can be merged into a single workspace using the 'Simulink' facility available in 'Matlab' (MATLAB, 2011).

\section{Discussion}

The suggested approach enables the quantitative values in a range to be distributed in relation to their significance. For instance, the left-hand side and right-hand side of a quantitative range have more relation to the previous and following qualitative category (i.e. $\mathrm{VH}, \mathrm{H}, \mathrm{M}$, etc.) respectively. In the suggested approach, the aforementioned relationship is consistently established with the help of MFs. Using a rule base, the different MFs are consistently interrelated incorporating the practical significance of the PoF and CoF in calculating the MII.

\section{Conclusion}

The suggested method enables gaps present to be mitigated, for instance inbetween $\mathrm{H}$ to $\mathrm{VH}$ (i.e. 48 to 6 months), L to M (i.e. 120 to 72 months), etc. In addition, the suggested method enables the experts' knowledge to be recycled. Such recycling provides the opportunity to reduce variability present in the analysis due to human error, inconsistency of awareness, lack of experience, etc. Alternatively, the use of the suggested approach facilitates the improvement of the quality of the MII calculation process in terms of time and accuracy. However, special attention should be paid to developing the MFs.

Future research should be carried out to investigate the effect of triangular vs. Gaussian MFs on the accuracy of the MII analysis process.

\section{References}

1. Ratnayake R. M. C., Markeset, T.: Maintaining Technical Integrity of Petroleum Flowlines on Offshore Installations: A Decision Support System for Inspection Planning, Proceedings of the ASME 2010 29th International Conference on Ocean, Offshore and Arctic Engineering, OMAE2010-20035 (2010).

2. Wang, W.: A Model of Multiple Nested Inspections at Different Intervals, Computers and Operations Research, 27 (6), 539-558 (2000).

3. Ratnayake, R. M. C.: A Decision Model for Executing Plant Strategy: Maintaining the Technical Integrity of Petroleum Flowlines", International Journal of Decision Sciences, Risk and Management (IDJRSM), 4 (1/2), 1-24 (2012). 
4. Ratnayake, R. M. C., Samarakoon, S. M. S. M. K., Markeset, T.: Maintenance Integrity: Managing Flange Inspections On Aging Offshore Production Facilities, Proceedings of the ASME 30th International Conference on Ocean, Offshore and Arctic Engineering, ISBN: 978-0-7918-4435-9.

5. Geary W.: Risk Based Inspection - A Case Study Evaluation of Onshore Process Plant, HSL/2002/20, Engineering Control Group, http://www.hse.gov.uk/research/hsl_pdf/2002/hsl02-20.pdf (2002) (accessed on 02.09.2013).

6. Kauer, R., Jovanovic, A., Angelsen, S., Vage, G.: Plant Asset Management RIMAP (Risk-Based Inspection and Maintenance for European Industries) the European Approach, ASME PVP-Vol. 488, Risk and Reliability and Evaluation of Components and Machinery, PVP2004-3020, (2004) http://www. tuvrealestate.com/uploads/images/1134986959023229878962/ ASME-RIMAP SanDiego2004.pdf (accessed on 02.09.2013).

7. Brown, S. J., May, I. L.: Risk-based Hazardous Protection and Prevention by Inspection and Maintenance, Trans. ASME Journal of Pressure Vessel Technology, 122 (3), 362-367(2003).

8. Scarf, P. A..: On the Application of Mathematical Models in Maintenance", European Journal of Operational Research, 99 (3), 493-506 (1997).

9. Ratnayake, R. M. C.: Utilization of Piping Inspection Data for Continuous Improvement: a Methodology to Visualize Coverage and Finding Rates, Proceedings of the 32nd International Conference on Ocean, Offshore and Arctic Engineering (OMAE2013), OMAE2013-10025(2013).

10. Ratnayake, R. M. C.: Plant Systems and Equipment Maintenance: Use of Fuzzy Logic for Criticality Assessment in NORSOK Standard Z-008", Proceedings of the IEEE International Conference on Industrial Engineering and Engineering Management (IEEM) (2013).

11. DNV-RP-G101: Risk Based Inspection of Offshore Topsides Static Mechanical Equipment, Det Norske Veritas (2010).

12. Lapa, C. M. F., Guimaraes, A. C. F.: Effect Analysis Fuzzy Inference System in Nuclear Problems using Approximate Reasoning", Annals of Nuclear Energy, 31 (107), 107-115 (2004).

13. Mamdani, E. H., Assilian, S.: An Experiment in Linguistic Synthesis with a Fuzzy Logic Controller", International Journal of Man-Machine Studies, 7 (1), 1-13 (1975).

14. Wang, L. X.: Adaptive Fuzzy Systems and Control-Design and Stability Analysis, University of California at Berkeley, PTR Prentice Hall, (1993).

15. Juang, Y. T., Changa, Y. T., Huangb, C. P.: Design of Fuzzy PID Controllers using Modified Triangular Membership Functions, Information Sciences, 178 (5), 1325-1333 (2008).

16. MATLAB: MATLAB 7.12.0 (R2011a): Fuzzy Logic Toolbox, 1984-2011 The MathWorks, Inc (2011). 